\title{
An evaluation of preterm kidney size and function over the first two years of life
}

\author{
Yogavijayan Kandasamy ${ }^{1,2,3} \cdot$ Donna Rudd ${ }^{4}$ Eugenie R Lumbers ${ }^{2,5} \cdot$ Roger Smith ${ }^{2}$
}

Received: 18 October 2019 / Revised: 20 March 2020 / Accepted: 24 March 2020 / Published online: 15 April 2020

(C) The Author(s) 2020

\begin{abstract}
Background We carried out a study to determine the impact of prematurity on kidney development in the first 2 years of life. Methods In this prospective study, extremely preterm neonates (gestation $<28$ weeks) were recruited and underwent assessments at 6,12, and 24 months of age. A cohort of neonates born term were also recruited and followed up for 24 months. The primary outcomes measured in this study were total kidney volume (TKV) and estimated glomerular filtration rate (eGFR); albuminuria and blood pressure measurements (all provided as mean (standard deviation)) were the secondary outcomes.

Results Fifty-three premature and 31 term neonates (control) were recruited. At the age of 24 months (corrected age), infants born preterm had significantly smaller TKV $(56.1(9.4)$ vs. $64.8(10.2) \mathrm{mL} ; P=0.006)$. There was no difference in eGFR. These preterm infants were smaller $(11.25(1.53)$ vs. $12.9(1.8) \mathrm{kg} ; P=0.002)$ and shorter $(83.8(3.0)$ vs. $86.3(3.4) \mathrm{cm} ; P=0.02)$ when compared with the control group. At 6,12, and 18 months respectively, preterm infants had, relative to their height, significantly smaller kidney volumes $(0.54(0.1)$ vs. $0.59(0.1) \mathrm{mL} / \mathrm{cm}, P=0.05 ; 0.61(0.1)$ vs.0.71 $(0.1) \mathrm{mL} / \mathrm{cm}, P=0.003$; and $0.67(0.1)$ vs.0.76 (0.1) $\mathrm{mL} / \mathrm{cm}, P=0.006)$.

Conclusions Relative to body length, TKV in premature infants is smaller. Since length reflects adult body proportions more accurately than BSA, TKV to height ratio may be a more important measure in the child. Despite smaller TKV (and therefore fewer nephrons), infants born prematurely achieve similar eGFRs in the first 24 months of life, probably due to single-nephron hyperfiltration.
\end{abstract}

Keywords Preterm infant $\cdot$ Kidney volume $\cdot$ Estimated glomerular filtration rate

\section{Introduction}

Preterm birth accounts for $11 \%$ of births worldwide [1], and with increased investment in perinatal health among

Yogavijayan Kandasamy

dryoga1@bigpond.com

1 Department of Neonatology, The Townsville Hospital, 100 Angus Smith Drive, Douglas, Queensland 4814, Australia

2 Mothers and Babies Research Centre, Hunter Medical Research Institute, HMRI, The University of Newcastle,

Newcastle, NSW 2310, Australia

3 College of Medicine and Dentistry, James Cook University, Douglas, QLD 4814, Australia

4 College of Public Health, Medical and Veterinary Sciences, James Cook University, Douglas, QLD 4814, Australia

5 School of Biomedical Sciences and Pharmacy, University of Newcastle, Newcastle, NSW 2310, Australia developing countries, the number of these infants surviving to adulthood is likely to increase [2]. Interventions such as antenatal steroids have improved survival [3], but the contribution of the oligonephropathy of prematurity [4] and its impact on the global burden of chronic kidney diseases (CKD) remain to be determined. The causes of CKD in ex-preterm infants are unknown, but there is evidence that prematurity leads to oligonephronia $[4,5]$.

In humans, nephrogenesis occurs in utero and is completed by 36 weeks of gestation. When an infant is born premature, normal nephrogenesis is interrupted [5]. Both animal [6] and human studies [7] indicate that ex-utero nephrogenesis continues for a short while after birth but a significant proportion of the new nephrons are abnormally developed. There is also data to indicate that prematurity changes the activity of the renin-angiotensin system [8].

The use of potentially nephrotoxic (yet clinically necessary) medications such as aminoglycosides, as well as sepsis, compounded by difficulties in detecting glomerular injury and kidney impairment, results in further nephron loss [9]. 
Brenner et al. $[10,11]$ demonstrated in animal models that single-nephron GFR increases to compensate for a reduction in the number of nephrons or when there are increased metabolic requirements. This compensatory increase is a response to the need to eliminate toxins and the end products of metabolism. Increased filtration per nephron thus occurs as an adaptive response to nephron loss; however, this can lead to glomerular hypertension, glomerulosclerosis, and a progressive decline in kidney function [12].

Nephron number can be estimated by kidney biopsy together with careful direct radiographic measurements of nephron mass [13]. Obviously, this is not a routine clinical tool. Fortunately, there are strong data that show a good correlation between kidney volume and nephron number in infants [14, 15]. In humans, while the neonatal consequences of prematurity have been described $[4,6,16]$, its long-term effects on kidney function during childhood remain to be determined. To bridge this gap in knowledge, we carried out a study to determine the impact of prematurity on kidney development in a cohort of extremely preterm infants from term corrected (37 postmenstrual age) until age 24 months.

\section{Methods}

This prospective study was conducted in the Department of Neonatology, Townsville Hospital, Queensland, Australia. The recruitment was conducted from August 2014 until October 2016, and follow-up was completed in October 2018. We have previously published the neonatal outcomes [16], and the data presented in this manuscript are follow-up data from the same cohort. Preterm infants at less than 28 weeks of gestation (extremely preterm infants), with birth weights between the 10th and 90th centile (appropriate for gestational age (AGA)), and admitted to the neonatal department during the study period were followed from term corrected (37 postmenstrual age (PMA)) upon discharge from the neonatal unit at ages of 6, 12, and 24 months. A cohort of term AGA infants admitted to the neonatal unit at the same time with minor neonatal conditions, such as jaundice or feeding problems, were recruited as a control group. The preterm infants were compared with a control group of similar corrected gestational age, to ensure that any differences found were not due to prematurity. Infants diagnosed with antenatal kidney abnormalities as reported by a radiologist were excluded.

The Townsville Health District Human Research Ethics Committee approved this study, which was conducted following the tenets of the Declaration of Helsinki. Written consent was obtained from parents of all infants who participated in this study. The primary outcomes from this study were total kidney volume (TKV) (a surrogate for nephron number) and estimated glomerular filtration rate (eGFR). Secondary outcomes were albuminuria and mean blood pressure measurements.

The methods used to determine kidney volume and other measurements (cystatin $\mathrm{C}$ and urine for albumin to creatinine ratio and statistical analysis) have been previously published [16]. Estimated glomerular filtration rate was calculated using the Zappitelli CysC eGFR equation (GFR ( $\mathrm{mL} / \mathrm{min}$ per $1.73 \mathrm{~m}^{2}$ ) $=75.94 /\left[\right.$ serum cystatin $\left.\mathrm{C}^{1.17}\right]$ ) [17]. Body surface area (BSA) was calculated using the Du Bois formula [18], which was then used to calculate the TKV/BSA ratio.

Blood pressure measurement was performed using a portable device (Welch Allyn Connex 3400 SureBP, Hillrom, Chicago, USA) with an appropriate cuff size and the mean blood pressure (MAP) was recorded. The infant usually sits on the parent's lap, and the measurements are taken twice (when the infant is calm) for an average measurement. MAP is the commonly used blood pressure indicator in a neonatal unit, and it represents the average perfusion pressure. A single MAP value is easier to trend; changes in MAP are easier to interpret than changes in systolic or diastolic pressures, which at times can move in different directions [19].

\section{Results}

During the study, 131 preterm infants less than 28 weeks of gestation were admitted to the neonatal unit. There were nine deaths. Consent was obtained for 59 infants, and one infant was excluded because of hydronephrosis. Complete data sets were available for 53 infants; 32 term infants were recruited as the control group. All infants were followed up at 6,12, and 24 months after discharge from the neonatal unit. At 24 months, infants born preterm had significantly smaller TKVs (56.1 (9.4) vs. $64.8(10.2) \mathrm{mL} ; P=0.006)$ although there was no difference in eGFR (102.1 (14.9) vs.104.6 (21.5) $\left.\mathrm{mL} / \mathrm{min} / 1.73 \mathrm{~m}^{2} ; P=0.7\right)$. These infants were smaller (11.25 (1.53) vs.12.9 (1.8) kg; $P=0.002)$ and shorter $(83.8$ (3.0) vs. $86.3(3.4) \mathrm{cm} ; P=0.02)$ compared with the control group. There were no significant differences in mean blood pressure (80.5 (11.0) vs. $75.6(9.5) \mathrm{mm} \mathrm{Hg}$ ) and urine albumin to creatinine ratio between preterm and control groups respectively. Table 1 summarizes the comparisons between infants born preterm and the control group at 6, 12, and 24 months. eGFR in both groups had plateaued by 24 months of age, as shown in Fig. 1, although differences in TKVs and body weights were still evident, as shown in Figs. 2 and 3 respectively. When corrected for BSA, there was no difference in TKV (TKV/BSA) between premature and term neonates (112 (14) vs. $\left.120(16) \mathrm{mL} / \mathrm{m}^{2} ; P=0.09\right)$. However, when corrected for length (TKV/length), preterm infants had significantly smaller kidney volume $(0.54(0.1)$ vs. $0.59(0.1) \mathrm{mL} / \mathrm{cm}$, $P=0.05 ; 0.61(0.1)$ vs. $0.71(0.1) \mathrm{mL} / \mathrm{cm}, P=0.003$; and 
Table 1 Comparison between infants born preterm and control at 6, 12, and 24 months of age

\begin{tabular}{|c|c|c|c|c|c|c|c|c|c|}
\hline & \multicolumn{3}{|l|}{6 months } & \multicolumn{3}{|l|}{12 months } & \multicolumn{3}{|l|}{24 months } \\
\hline & Preterm & Control (term) & $P$ value & Preterm & Control (term) & $P$ value & Preterm & Control (term) & $P$ value \\
\hline Weight (kg) & $6.6(1.1)$ & $7.9(1.0)$ & $<0.001 *$ & $8.7(1.3)$ & $10.0(1.1)$ & $<0.001 *$ & $11.2(1.5)$ & $12.9(1.8)$ & $0.002 *$ \\
\hline Length (cm) & $64.1(2.9)$ & $67.5(3.1)$ & $<0.001 *$ & $73.1(3.5)$ & $75.6(2.9)$ & $0.01 *$ & $83.8(3.0)$ & $86.3(3.4)$ & $0.02 *$ \\
\hline Total kidney volume (mL) & $34.5(7.3)$ & $39.8(7.4)$ & $0.006 *$ & $44.5(9.4)$ & $53.8(10.4)$ & $0.001 *$ & $56.1(9.4)$ & $64.8(10.2)$ & $0.01 *$ \\
\hline eGFR (mL/min/1.73 m²) & $69.2(14.4)$ & $77.1(12.4)$ & $0.04^{*}$ & $85.5(13.3)$ & $93.1(20.2)$ & 0.12 & $102.1(14.9)$ & $104.6(21.5)$ & 0.70 \\
\hline
\end{tabular}

$e G F R$, estimated glomerular filtration rate

* Statistically significant difference $(P<0.05)$

$0.67(0.1)$ vs. $0.76(0.1) \mathrm{mL} / \mathrm{cm}, P=0.006)$ at 6,12 , and 18 months respectively.

Figure 4 shows that TKV in both premature and control cohorts shows significant positive (Pearson's) correlation between TKV and eGFR in the first 24 months.

\section{Discussion}

Infant GFR peaks by the age of 2 years [20, 21]; our data for both term and preterm infants show a similar trend in Fig. 1. Height-adjusted TKVs in premature infants were significantly smaller when compared with the control group. Heightadjusted TKVs have been found to be useful in predicting the onset of kidney insufficiency in certain forms of cystic kidney disease [22]. We suggest that they may be more useful than TKV to BSA ratios for assessing kidney development in premature infants. Despite having smaller kidney volumes (hence reduced nephron numbers), preterm infants had eGFRs similar to those measured in infants born at term (control). We propose that preterm infants achieve an eGFR similar to term infants despite having fewer nephrons probably by single-nephron hyperfiltration, thus putting these infants on a trajectory to develop CKD [23, 24]. As nephrogenesis occurs in utero, the increase in eGFR as shown in Fig. 4 is likely to be due to an increase in kidney blood flow, glomerulomegaly, and an increase in kidney tubular length (the last two result in an increased TKV).

Keijzer-Veen et al. [25] assessed kidney function and kidney size in a cohort of 29 young adults (20 years old) who were born preterm ( $<32$ weeks' gestation). They did not find any difference in kidney function and kidney size between the preterm and control groups. However, more recent studies involving extremely preterm infants (born earlier at < 28 weeks gestation) show a different trend. Rakow et al. [26] followed up a cohort of 40 extremely preterm (< 28 weeks) infants until the age of 7 years. The investigators found that at 7 years of age, these children had significantly smaller kidney volumes but there were no significant differences in their eGFRs or blood pressures. In another study, Vollsaeter et al. [27] published data, collected at age 11 years, from a cohort of 57 children who were also born extremely preterm ( $<28$ weeks). In this study, the investigators reported that eGFRs in these children were significantly lower when
Fig. 1 Fitted quadratic regression curve for eGFR $\left(\mathrm{mL} / \mathrm{min} / 1.73 \mathrm{~m}^{2}\right)$ in preterm and control infants in the first 2 years of life

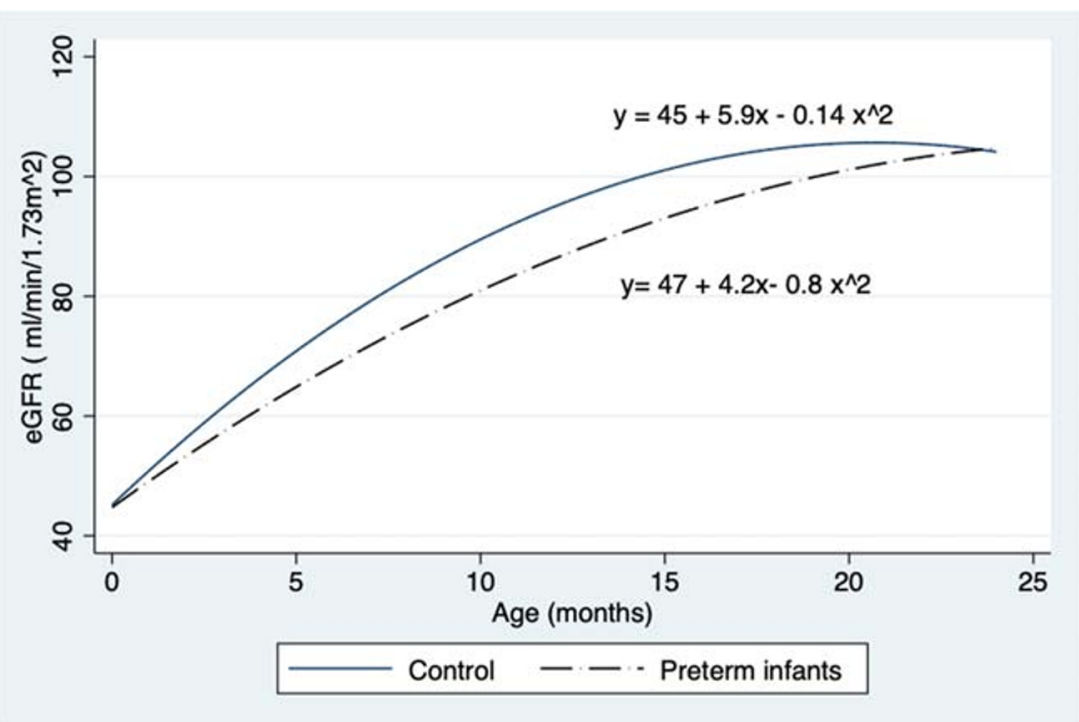


Fig. 2 Fitted quadratic regression curves comparing total kidney volumes (TKV) between preterm infants and controls

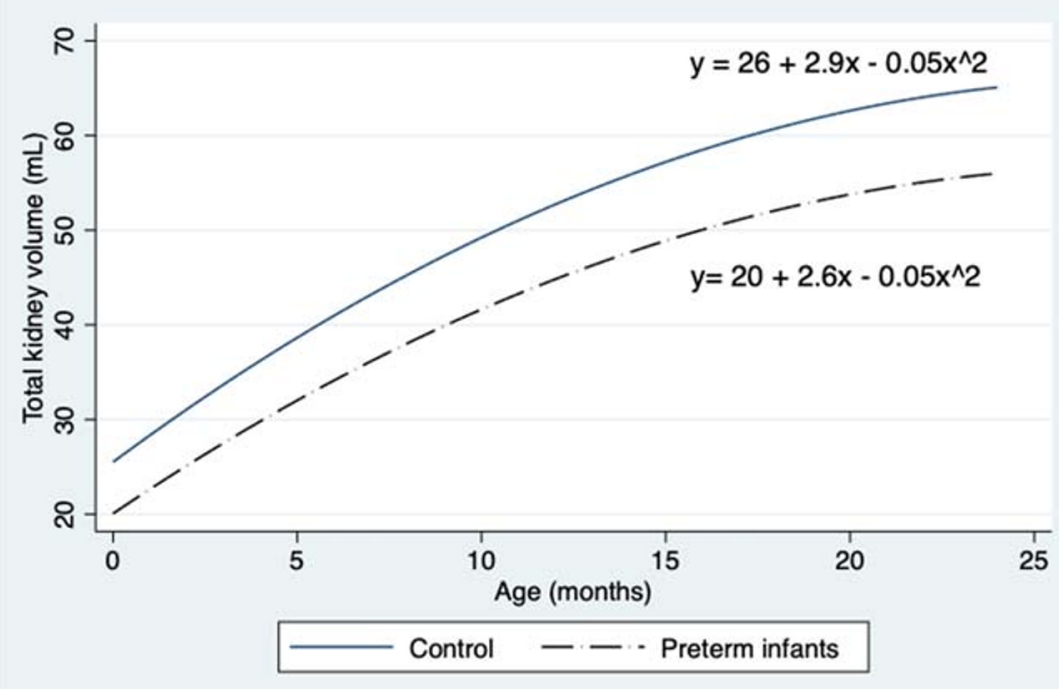

compared with the control (term) group. There was no significant difference in blood pressure. More recently, South et al. [28] published follow-up data from a cohort of 96 adolescents (14 years) who were born preterm $(<28$ weeks) and showed that these children had high blood pressures and lower eGFRs compared with their peers who were born at term. Our study follows extremely preterm infants of similar gestational age $(<28$ weeks $)$ as the above three studies and it is likely that the impact of prematurity on nephrogenesis is more profound in smaller and more preterm infants, especially those $<28$ weeks of gestation. We postulate that preterm infants have glomerular hyperfiltration within the first week of life [16], and this continues during infancy and childhood, so that they show signs of kidney impairment by puberty and adolescence [27, 28]. It is plausible that the increase in GFR after puberty cannot keep up with the growth surges a child experiences during puberty and its associated increased metabolic demand and hormonal changes, which eventually lead to high blood pressure.

Most preterm infants' follow-up plans involve regular assessment until the age of 24 months, which is followed by a formal neurodevelopmental assessment. These infants often have their weight, length, and head circumference measured [29]. Kidney function as measured by urine analysis for proteinuria, blood pressure, and eGFR using cystatin $\mathrm{C}$ are not part of their routine assessment. We recommend that for infants born $<28$ weeks gestation these parameters of kidney function are routinely measured at 2 years of age, and at adolescence when the first signs of kidney impairment may become clinically evident.
Fig. 3 Fitted quadratic regression curve comparing body weights between preterm infants and controls

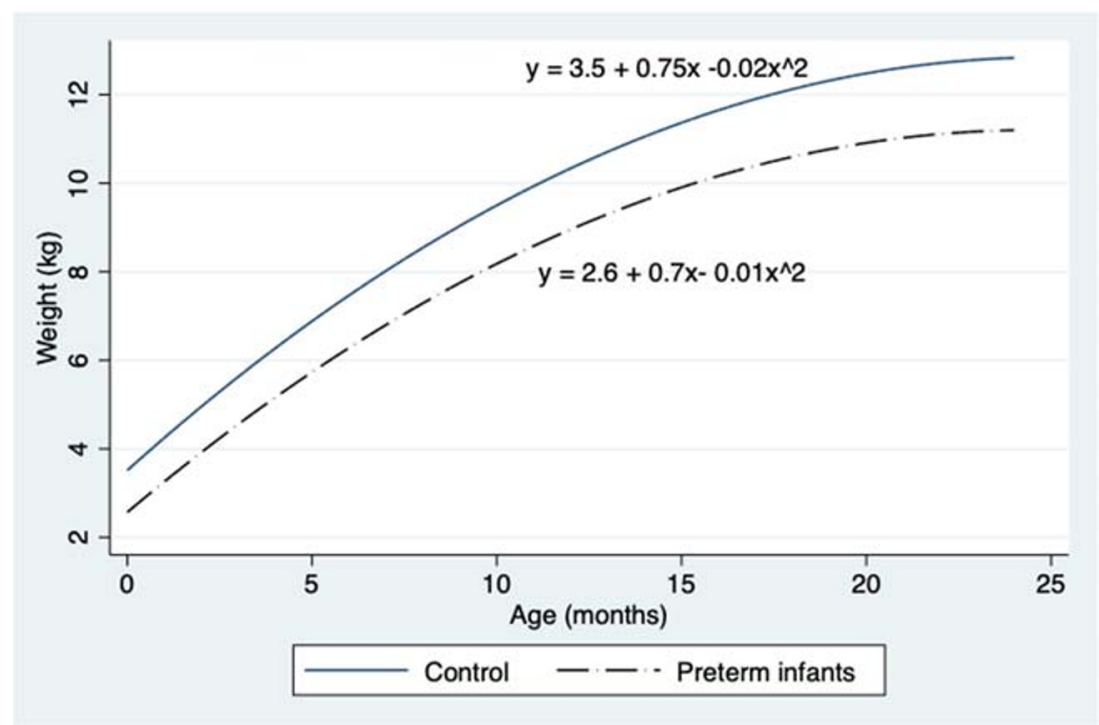


Fig. 4 Premature and control cohorts show significant positive (Pearson's) correlation between TKV and eGFR in the first 24 months

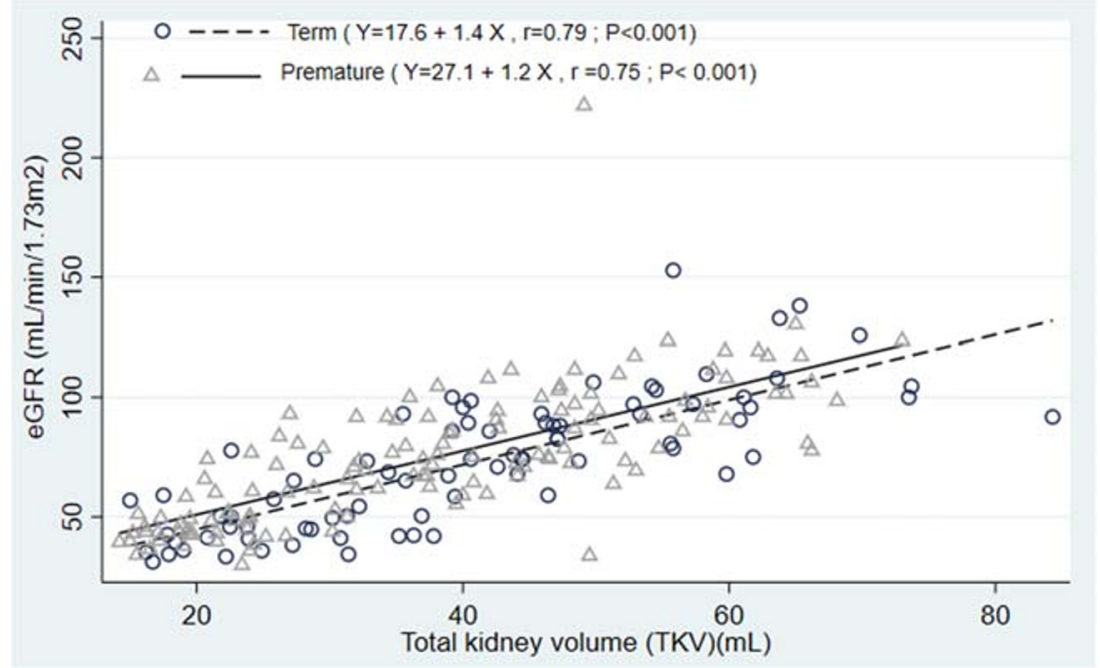

Our study has a few limitations. Firstly, our sample size was limited, especially for the control group. Approximately $40 \%$ of the patients in our cohort are from rural and regional areas and were not keen/able to travel to the study site for regular assessment, so six subjects were lost to follow-up. It is rather challenging to have parents of normal infants attend regular follow-ups and to subject the infants to regular venepuncture, when it is not clinically indicated. So, we are very grateful to all parents who willingly enrol their infant for clinical studies. In our study, we used eGFR to determine kidney function, using Zappitelli's equation [17]. Regular GFR measurement in children using the inulin method is not practical in the clinical setting. We used the Du Bois method to estimate BSA area, and this is only an approximation of the actual BSA. While the sonographer was blinded to the clinical data, it is always possible for the sonographer to guess this clinical status (preterm or term) based on other parameters such as plagiocephaly, which occurs in preterm infants.

\section{Conclusion}

Relative to body length, TKVs in premature infants are smaller. Despite having smaller kidney volumes (and therefore reduced nephron numbers), preterm infants have an eGFR similar to term infants (control). There was no difference in blood pressure and the urine albumin to creatinine (ACR) ratios between the two cohorts. Preterm infants achieve similar eGFRs to term infants, probably by single-nephron hyperfiltration. This puts them on a trajectory that could lead to intraglomerular hypertension and glomerulosclerosis. Follow-up of preterm infants should include routine assessment of the kidney function (eGFR and ACR) and blood pressure.
Acknowledgments We like to thank Ms. Helena McInnes, Ms. Jessica Bowron, Mrs. Sonja Brennan, and the participants and their families.

Funding information The study was funded by the National Health and Medical Research Centre.

\section{Compliance with ethical standards}

The Townsville Health District Human Research Ethics Committee approved this study, which was conducted following the tenets of the Declaration of Helsinki. Written consent was obtained from parents of all infants who participated in this study.

Conflict of interest The authors have no conflict of interest to declare.

Open Access This article is licensed under a Creative Commons Attribution 4.0 International License, which permits use, sharing, adaptation, distribution and reproduction in any medium or format, as long as you give appropriate credit to the original author(s) and the source, provide a link to the Creative Commons licence, and indicate if changes were made. The images or other third party material in this article are included in the article's Creative Commons licence, unless indicated otherwise in a credit line to the material. If material is not included in the article's Creative Commons licence and your intended use is not permitted by statutory regulation or exceeds the permitted use, you will need to obtain permission directly from the copyright holder. To view a copy of this licence, visit http://creativecommons.org/licenses/by/4.0/.

\section{References}

1. Vogel JP, Chawanpaiboon S, Moller A-B, Watananirun K, Bonet M, Lumbiganon P (2018) The global epidemiology of preterm birth. Best Pract Res Clin Obstet Gynaecol 52:3-12

2. Liao X-P, Chipenda-Dansokho S, Lewin A, Abdelouahab N, Wei S-Q (2017) Advanced neonatal medicine in China: a national baseline database. PLoS One 12:e169970-e0169970

3. Roberts D, Brown J, Medley N, Dalziel SR (2017) Antenatal corticosteroids for accelerating fetal lung maturation for women at risk of preterm birth. Cochrane Database Syst Rev 3:CD004454CD004454 
4. Kandasamy Y, Smith R, Wright IMR (2012) Oligonephropathy of prematurity. Am J Perinatol 29:115-120

5. Abitbol CL, Rodriguez MM (2012) The long-term renal and cardiovascular consequences of prematurity. Nat Rev Nephrol 8:265274

6. Gubhaju L, Sutherland MR, Yoder BA, Zulli A, Bertram JF, Black MJ (2009) Is nephrogenesis affected by preterm birth? Studies in a non-human primate model. Am J Physiol Renal Physiol 297:F1668

7. Sutherland MR, Gubhaju L, Moore L, Kent AL, Dahlstrom JE, Horne RSC, Hoy WE, Bertram JF, Black MJ (2011) Accelerated maturation and abnormal morphology in the preterm neonatal kidney. J Am Soc Nephrol 22:1365-1374

8. South AM, Nixon PA, Chappell MC, Diz DI, Russell GB, Jensen ET, Shaltout HA, O Shea TM, Washburn LK (2018) Association between preterm birth and the renin-angiotensin system in adolescence: influence of sex and obesity. J Hypertens 36:2092-2101

9. Bakhoum CY, Basalely A, Koppel RI, Sethna CB (2019) Acute kidney injury in preterm infants with necrotizing enterocolitis. $\mathrm{J}$ Matern Fetal Neonatal Med 32:3185-3190

10. Marsh AC, Lumbers ER, Gibson KJ (2002) Renal, cardiovascular and endocrine responses of fetal sheep at 0.8 of gestation to an infusion of amino acids. J Physiol 540:717-728

11. Kawata I, Koshi T, Hirabayashi K, Koike H, Sato Y, Yamashita K, Oguchi T, Aizawa T (2019) Prediabetes defined by the International Expert Committee as a risk for development of glomerular hyperfiltration. Acta Diabetol 56:525-529

12. Helal I, Fick-Brosnahan GM, Reed-Gitomer B, Schrier RW (2012) Glomerular hyperfiltration: definitions, mechanisms and clinical implications. Nat Rev Nephrol 8:293

13. Tsuboi N, Kanzaki G, Koike K, Kawamura T, Ogura M, Yokoo T (2014) Clinicopathological assessment of the nephron number. Clin Kidney J 7:107-114

14. Nyengaard JR, Bendtsen TF (1992) Glomerular number and size in relation to age, kidney weight, and body surface in normal man. Anat Rec 232:194-201

15. Zhang Z, Quinlan J, Hoy W, Hughson MD, Lemire M, Hudson T, Hueber P-A, Benjamin A, Roy A, Pascuet E, Goodyer M, Raju C, Houghton F, Bertram J, Goodyer P (2008) A common RET variant is associated with reduced newborn kidney size and function. J Am Soc Nephrol 19:2027-2034

16. Kandasamy Y, Rudd D, Smith R, Lumbers ER, Wright IM (2018) Extra uterine development of preterm kidneys. Pediatr Nephrol 33: $1007-1012$

17. Zappitelli M, Parvex P, Joseph L, Paradis G, Grey V, Lau S, Bell L (2006) Derivation and validation of cystatin C-based prediction equations for GFR in children. Am J Kidney Dis 48:221-230
18. Du Bois D, Du Bois EF (1916) Clinical calorimetry: tenth paper a formula to estimate the approximate surface area if height and weight be known. JAMA Intern Med XVII:863-871

19. Stebor AD (2005) Basic principles of noninvasive blood pressure measurements in infants. Adv Neonatal Care 5:252-261

20. Heilbron DC, Holliday MA, Al-Dahwi A, Kogan BA (1991) Expressing glomerular filtration rate in children 5:5-11. Pediatr Nephrol 5:5-11

21. Mian AN, Schwartz GJ (2017) Measurement and estimation of glomerular filtration rate in children. Adv Chronic Kidney Dis 24: 348-356

22. Chapman AB, Bost JE, Torres VE, Guay-Woodford L, Bae KT, Landsittel D, Li J, King BF, Martin D, Wetzel LH, Lockhart ME, Harris PC, Moxey-Mims M, Flessner M, Bennett WM, Grantham JJ (2012) Kidney volume and functional outcomes in autosomal dominant polycystic kidney disease. Clin J Am Soc Nephrol 7: 479-486

23. Hostetter TH, Olson JL, Rennke HG, Venkatachalam MA, Brenner BM (1981) Hyperfiltration in remnant nephrons: a potentially adverse response to renal ablation. Am J Physiol Renal Physiol 241: F85-F93

24. Brenner BM, Troy JL, Daugharty TM, Deen WM, Robertson CR (1972) Dynamics of glomerular ultrafiltration in the rat. II. Plasmaflow dependence of GFR. Am J Phys 223:1184-1190

25. Keijzer-Veen MG, Kleinveld HA, Lequin MH, Dekker FW, Nauta J, de Rijke YB, van der Heijden BJ (2007) Renal function and size at young adult age after intrauterine growth restriction and very premature birth. Am J Kidney Dis 50:542-551

26. Rakow A, Laestadius Å, Liliemark U, Backheden M, Legnevall L, Kaiser S, Vanpée M (2019) Kidney volume, kidney function, and ambulatory blood pressure in children born extremely preterm with and without nephrocalcinosis. Pediatr Nephrol 34:1765-1776

27. Vollsæter M, Halvorsen T, Markestad T, Øymar K, Ueland PM, Meyer K, Midttun Ø, Bjørke-Monsen A-L (2018) Renal function and blood pressure in 11 year old children born extremely preterm or small for gestational age. PLoS One 13:e0205558-e0205558

28. South AM, Nixon PA, Chappell MC, Diz DI, Russell GB, Jensen ET, Shaltout HA, O'Shea TM, Washburn LK (2019) Renal function and blood pressure are altered in adolescents born preterm. Pediatr Nephrol 34:137-144

29. National Institute for Health and Care Excellence (2017) Developmental follow-up of children and young people born preterm at: https://www.nice.org.uk/guidance/ng72 [Accessed 02 September 2019]

Publisher's note Springer Nature remains neutral with regard to jurisdictional claims in published maps and institutional affiliations. 